\title{
The Effect of Alternative Assessment Techniques on EFL Learners' Reading Comprehension Ability and Self-efficacy in Reading: The Case of Iranian Junior High School Students
}

\author{
Seyed Hesamuudin Aliasin ${ }^{1, *}$, Mehdi Amanlu² \\ ${ }^{1}$ Faculty of Humanities, University of Zanjan, Iran \\ ${ }^{2}$ General Office of Education, Iran
}

Copyright $\mathrm{O} 2017$ by authors, all rights reserved. Authors agree that this article remains permanently open access under the terms of the Creative Commons Attribution License 4.0 International License

\begin{abstract}
Self-efficacy plays a major role in learners' ultimate success. The present study investigated the effect of alternative assessment techniques of reading comprehension on the participants' self-efficacy in reading and their performance in reading comprehension. Matching items, gap filling items, C-tests, editing tasks and ordering techniques were used as alternative assessment techniques as replacements to traditional techniques such as multiplechoice type or essay- type items. Based on the proficiency test results, 77 intermediate junior high school students were selected from among 99 students in intact classes as the participants. The instruments included an adapted self-efficacy-in-reading questionnaire, the KET test and a reading comprehension test developed and piloted by the researchers. The results of t-test analyses indicated that the learners were significantly aware of self-efficacy while involved in reading comprehension of their English textbook texts. In other words, the participants possessed high self-efficacy in reading as measured by the questionnaire mentioned above. However, the findings revealed no significant effect for the use of alternative assessment techniques on the participants' self-efficacy in reading comprehension. Finally, the t-test results indicated a significant effect for the use of alternative assessment techniques on the participants' performance on the reading comprehension test.
\end{abstract}

Keywords Reading Comprehension, Reading Comprehension Assessment, Alternative Assessment Techniques, Self-efficacy in Reading, EFL, TESOL

\section{Introduction}

Since the introduction of humanistic approach many, scholars [1-3] have considered 'affect' as one of the main determining elements of success in learning foreign or second languages. Affect involves variables such as attitudes, motivation, interest, learners' beliefs, expectations, and prior experiences [4, 5], as cited in Gee [5], (3). The present study focuses on learners' self-efficacy beliefs as one of the facets of affectivity. According to Bandura [6] (391), 'self-efficacy' beliefs refer to "people's judgments of their capabilities to organize and execute courses of action required to attain designated types of performances." With Bandura [6], learners' beliefs about their self-efficacy have proved to be a much more consistent predictor of behavior than any other closely-related variables. One area in which foreign language learners experience a great deal of hardship and disappointment is concerned with reading comprehension assessment in a fixed and unvarying system. Bachman [7] asserts that such 'institutionalized' item types in language testing lead to a wide, common and frequent use of some item forms or question types which causes students to feel unable to handle a new form or a new type of assessment. In addition, Anderson [8] maintains that using only one method in testing understanding of a text proves to be an inadequate sort of measurement. For this reason, the present study has sought to investigate the effect of alternative and varying assessment techniques of reading comprehension on EFL learners' self-efficacy in reading and their reading comprehension ability.

\section{Background}

\subsection{Alternative Assessment versus Traditional Assessment}

Also known as performance assessment, alternative 
assessment refers to "procedures and techniques which can be used within the context of instruction and can be easily incorporated into the daily activities of the school or classroom" [9], as cited in Hamayan [10], (213). Alternative assessment does not mean to compare an individual to a large group beyond the students in a given classroom. As a result, under the realm of alternative assessment procedure a more holistic evaluation becomes possible [11]. Utilizing a variety of assessment options, educators would be able to meet numerous instructional strategies in the classroom. As a practical example for alternative assessment, one can consider Assessment, Articulation, Accountability, a three-year project proposed by The North Carolina Department of Public Instruction in 1999 aimed at improving and expanding foreign language study for elementary and secondary school students through development of a variety of assessment tools. Opponents of alternative assessment favor ongoing assessments through which students' performance and progress over a period of time are measured. Traditional testing, in contrast, is a 'one-time measure' by which students' performance in a particular-day scale accounts for their overall achievement. Also, it is worth mentioning that emphasis on alternative assessment does not mean a total refutation of traditional testing methods. Rather, an ultimate goal in this approach is to establish a balanced linkage within the two modules of the traditional and modern outlook.

Citing some sources, Dikli [12], (15) highlights the contrastive features of traditional and alternative assessment as follows:

According to Bailey [13], traditional assessments are indirect and inauthentic. She also adds that traditional assessment is standardized and for that reason, they are one-shot, speed-based, and norm-referenced. Law and Eckes [14] underline the same issue and state that traditional assessments are single-occasion tests. That is, they measure what learners can do at a particular time. However, test scores cannot tell about the progression of child. Similarly, they cannot tell what particular difficulties the students had during the test. Bailey [13] also mentions that there is no feedback provided to learners in this type of assessment. The projects are mainly individualized and the assessment procedure is decontextualized. Law and Eckes [14] point out most standardized tests assess only the lower-order thinking skills of the learner. Similarly, Simonson et al.[15] state that traditional assessment often focus on learner's ability of memorization and recall, which are lower level of cognition skills. Additionally, traditional assessment tools require learners to display their knowledge in a predetermined way (Brualdi, [16]).

Alternative assessments, on the other hand, assess higher-order thinking skills. Students have the opportunity to demonstrate what they learned. This type of assessment tools focus on the growth and the performance of the student. That is, if a learner fails to perform a given task at a particular time, s/he still has the opportunity to demonstrate his/her ability at a different time and different situation. Since alternative assessment is developed in context and over time, the teacher has a chance to measure the strengths and weaknesses of the student in a variety of areas and situations, [14].

Among other factors that contributed to favored attention to alternative assessment in contrast to traditional assessment, two key factors paved the ground for a movement toward alternative assessment. The first one has to do with the increasing importance of the relationship between assessment and both teaching and learning. The change in assessment procedure was due to the interwoven nature of assessment and learning. Alternative assessment aimed to reflect the process of learning [17, 18], as cited in Hamayon [10]. The second factor deals with the evolving nature of educational goals toward more sophisticated and higher standards supporting holistic and integrative views of language in contrast to what has been the case for the last twenty years [19, 20], as cited in Hamayon [10].

\subsection{Commonly Used Traditional and Alternative Assessment Techniques in Reading Comprehension}

Commonly used traditional techniques in assessing reading comprehension skill include essay-type, multiple-choice type and true-false items. The essay-type questions are those items that require the EFL learners to exhibit their understanding of the reading passages through answering them in writing. Although easy to construct, the responses for essay-type items must be given in the target language which makes it an invalid type of question since in such items reading comprehension skill is assessed through a different skill; i.e. writing (Nuttall, [21]). Multiple-choice type items are both easily and objectively scored. However, there are also a number of caveats regarding this technique listed by Hughes [22]. He believes that multiple-choice items only test recognition rather than comprehension, restrict what can be tested, allow for guessing and cheating, and have harmful wash-back effects. Finally, despite the fact that true-false items are easy to construct and readily lend themselves to objective scoring, they suffer from successful guessing by 50 percent. This pitfall becomes even more problematic when the correct choice is 'False', which makes it much more difficult to discover whether the test-taker really knows the correct response [15].

As for the alternative assessment techniques in reading comprehension assessment, the following tasks reviewed by Mazlum Zavarag [23] constituted the majority of alternative assessment techniques in the present study.

\subsubsection{Gap Filling Tests}

Gap filling test is a test in which every n-th word is deleted from the text in a pseudo random procedure. There are two different ways to construct such test: deleting function words 
(to focus on grammar) or deleting content words (to assess students' comprehension of the overall meaning).

\subsubsection{Matching Techniques}

The test consists of two sets of stimuli matched against each other. For reading passages, two or more paragraphs are omitted from the original texts. Students are required to fit the missing paragraphs into the numbered gaps. Students would need to activate their ability of understanding the coherence and cohesion of the text. Also, the knowledge of the paragraph organization is assessed by the matching technique.

\subsubsection{Ordering Techniques}

Unlike matching technique, the ordering techniques require the test-takers unscramble a set of words, sentences, paragraphs or texts using their sense of paragraph unity. The first sentence or paragraph should be provided for the candidates.

\subsubsection{Editing Tasks}

Passages consist of erroneous phrases or structures in which the test-takers are required to identify them and offer the appropriate forms. Both function words and content words can be assessed using editing tasks. Weir (1990) believes that since editing tasks encourage learners to make an attempt to edit their own written work more carefully, they may provide a good wash-back effect on learners.

\subsubsection{The C-test}

The second half of every second word is deleted. The candidates must restore the words to their original form.

\subsubsection{The Free Recall Test}

In free recall tests, students are given an opportunity to read a passage in foreign language, to cover the text, then to write down whatever comes to their mind. The point in utilizing such tests is that the recall must be in learners' first language since students might not possess L2 writing skills.

\subsubsection{The Cloze elide Test (Negative Cloze)}

The cloze elide tests require that test designer insert words into text rather than deleting them.

The test takers are supposed to identify those extra words and cross them out.

\subsubsection{Information-transfer Techniques}

The test taker is asked to look for required information and transfer it to charts, diagrams or tables. To handle such a test, students would need to scan the text, therefore, a valuable means to assess their scanning skill

\subsection{Self-efficacy}

It has been well documented that affective variables can contribute more to foreign or second language learning than do aptitude, intelligence, teaching methods used in the classroom, or time spent on language learning (see [24], (279)). Hilgard [3], a distinguished scholar in human learning and cognition, once noted that "purely cognitive theories of learning will be rejected unless a role is assigned to affectivity" (267), as cited in Brown [25]. For this reason, self-efficacy beliefs constitute the main concern of the present study. 'Self-efficacy' refers to an individual's belief in his or her capacity to execute behaviors necessary to produce specific performance attainment [26]. Since the concept of self-efficacy was introduced later into language learning issues, there has been a lack of rich background in the field. However, existing studies point out a positive link between self-efficacy and L2 achievements. Wu [27] found that language achievement is affected positively when students possess high self-efficacy beliefs of learning a second language. Another study on the effect of self-efficacy on school students' achievement in math and English revealed that self-efficacy is a strong predictor of math and English achievement [28], as cited in [29].

According to Alfassi [30], reading is a complex cognitive activity essential for sufficient functioning and for obtaining information in modern society. Therefore, one can realize the vital importance of optimal level of self-efficacy in reading and the role it can play in students' academic achievement. Bandura [26] identifies four major sources of information that are primary in the development of self-efficacy beliefs: 1) mastery experiences (our achievements raise our level of self-efficacy), 2) vicarious experiences (other individuals' achievements motivate us to believe that we have the same ability in gaining achievements), 3) social and verbal persuasion (what other people say can influence our beliefs about our abilities), and 4) psychological states (anxiety, stress, and fear can influence our behavior).

A considerable body of research suggests that teachers can often help low self- efficacious learners by linking new work to recent success (Badura's mastery experiences), teaching needed learning strategies, reinforcing effort and persistence, stressing peer modeling, teaching struggling learners to make facilitative attribution, and helping them identify or create personally important goal $[31,32,33,29,34,35]$, as cited in [36]. McCabe and Margolis [37] as well as Ferrara [38] found that teachers can have a positive impact on students' self-efficacy in reading by directing classroom activities through easier tasks to gradually more challenging ones, setting attainable goals and assisting students in meeting those goals and finally having students participate in paired reading and repeated readings. In another study, Dinthy, Docky and Segers [39] explored the factors affecting students' self-efficacy in higher education. They concluded that students' self-efficacy is decreased when 'repeated strong negative mastery experiences' is developed in students' academic life. In another comprehensive study, Shellberg [40] explored self-efficacy in reading and found out that students in his study were making progress as readers and were able to define characteristics of a good reader. Also, in a 
study conducted by Khajavi and Ketabi [41], it was revealed that students' self-efficacy in reading comprehension improves as the consequence of concept mapping strategy instructions. Zareh and Mobarakeh [42] studied the relationship between self-efficacy and use of reading strategy. They found that the participants felt an average confidence about their capability to perform general reading tasks. In contrast, two separately conducted studies led to completely different results. In fact, Rahemi [43] and Nasrollahi and Barjasteh [44] reported that the participants in their study did not possess an appropriate level of self-efficacy in reading. In one closely related research, Alkharusi's [45] study revealed that learners' self-efficacy on performance-approach goal within a classroom and the utilization of alternative assessments were jointly dependent factors.

\subsection{Alternative Assessment and Self-efficacy}

According to Margolis and McCabe [36], teachers have the responsibility to systematically stress the development of high self-efficacy. They also maintain that struggling readers with low self- efficacy must succeed on the very type of the task they expect to fail. The classroom tasks and homework should strengthen expectation of success rather than failure. Once learners experience repeated failure on traditional reading comprehension activities, they begin to develop a sense of low self-efficacy. Research on the effects of alternative assessment on student motivation and self-efficacy suggests that motivation levels and self-efficacy reached higher levels when students were engaged in alternative assessment [46]. Alternative assessment techniques can strengthen the circumstances in which learners with low self-efficacy experience the state of mastering on a task, thus helping those struggling learners persist on the future tasks. This is in line with the first source of efficacy information proposed by Bandura [26]. Given this focus on alternative assessment in the literature, this study was launched to investigate its possible effects on EFL learners' self-efficacy in reading comprehension skill. Thus, the researchers sought to answer the following questions: (1) Do Iranian Junior High School EFL learners possess selfefficacy while reading their textbook passages? (2) Does applying alternative reading comprehension assessment techniques improve Iranian Junior High School EFL learners' self-efficacy in reading their textbook passages? (3) Does applying alternative reading comprehension assessment techniques improve Iranian Junior High School EFL learners' performance on the reading comprehension test based on their textbook reading passages?

\section{Methodology}

\subsection{Participants}

Seventy-seven male junior high school students in Zanjan,
Iran, participated in the study. They had taken EFL courses for three years at junior high school and one year at high school. The first language of the students varied between two languages: Persian and Azeri Turkic. Some of the students also had taken some English classes in private language institutes. The participants were randomly divided into two groups: experimental $(n=40)$ and control $(n=37)$; the former received alternative assessment techniques of reading comprehension while the latter were exposed to the traditional techniques of reading comprehension assessment.

\subsection{Instruments}

In order to measure the participants' language proficiency and to achieve homogeneous groups, the Key English Test for Schools (KET) by Cambridge University Press was utilized. This test was chosen because it is a worldwide known standard test that enjoys a high content validity regarding the content of the Iranian English language textbook for Junior High School as indicated by the peer and expert judgments described below.

To come up with a scale to assess the participants' self-efficacy, the researchers studied the following self-efficacy scales. Accordingly, they adapted a scale for self-efficacy in reading comprehension for their own research context.

1 The General Self-efficacy Scale developed by Nezami, Schwarzer and Jerusalem [47].

2 Morgan-Jinks Student Efficacy Scale (MJSES) constructed by Jinks and Morgan [48].

3 Beliefs about Language Learning Inventory (BALLI) designed by Horwitz [49].

The General Self-efficacy Scale developed by [47] was a Persian (Farsi) adaptation of the English version of General Self-Efficacy Scale first developed by Schwarzer and Jerusalem [48]. The questionnaire contains 10 4-point Likert type items. The MJSES also consists of 34 4-point Likert type items intended to measure students' general self-efficacy beliefs. The BALLI questionnaire consists of 34 5-point Likert type items representing beliefs that some people hold about learning foreign languages.

The new scale for measuring EFL learners' self-efficacy in reading comprehension was adapted from the above mentioned measures, and it consisted of 20 5-point Likert type items. Based on the scale, the students were asked to read each item and rate how much they agreed or disagreed with the statement using a five-point Likert type items $(1=$ strongly disagree, $2=$ disagree, $3=$ no idea, $4=$ agree, $5=$ strongly disagree). The Cronbach alpha for the reliability of the questionnaire was calculated at 0.71 which indicated a satisfactory index.

The other instrument used in this study to assess the participants' performance on reading comprehension consisted of two paralleled reading comprehension tests at the same text difficulty level based on Iranian Junior High School English Textbook (see below), one before treatment 
as the pretest and the other after treatment as the posttest. The tests consisted of two short passages each followed by 10 reading comprehension question items. Several teachers and experts studied the test content thoroughly and confirmed its validity. The Cronbach alpha for the reliability of the test was calculated at 0.82 which indicated a satisfactory index.

\subsection{Procedure}

At the first stage, the participants in both experimental and control groups responded to the Self-Efficacy in Reading Questionnaire. The Participants in both groups were then given the reading comprehension pretest in order to ensure their homogeneity before treatment. Then, the participants in the experimental group received treatment which included a pack of alternative assessment tasks on various aspect of reading comprehension skill, as described above. Great effort was made to develop the tasks in such a manner that learners could handle them in a satisfactory way. Attempt was made to assess the participants' performance immediately after the completion of each task. The assessment was carried out either in terms of written feedback on the paper or oral feedback including immediate guidelines and suggestions to individual participants; the control group merely received the traditional assessment techniques for reading comprehension during the study. The treatment started at 7 October 2013 and finished at 4 December 2013 for 8 sessions. The participants' reading comprehension was assessed on a regular base. In each classroom session, at least two assessment techniques were employed. As the treatment was over, the participants again attempted the Self-efficacy-in-reading Questionnaire. Also, the reading comprehension posttest was administered. It is worth mentioning that the readability of the passages for the participants was checked via the Fog readability index, which resulted in appropriate readability level for the participants as the targeted readers (Fog index $=7.2$ ).

\subsection{Data Analysis}

To answer the questions addressed by the study, the researchers conducted a One-sample t-test analysis for the participants' performance on the Self-efficacy-in-Reading Questionnaire in order to investigate the first question whether Iranian Junior High School EFL learners possess self-efficacy while reading their textbook passages.. However, as a prerequisite to the t-test analysis, the one sample Kolmogorov-Smirnov test was run to ensure the normality of distribution for the participants' scores on the questionnaire at both the pre-treatment and post-treatment phases of the study. For the second and third questions, separate independent-samples t-tests were run to compare the groups' mean scores on the post-treatment Reading Self-efficacy Questionnaire and the reading comprehension posttests, respectively.

\section{Results and Findings}

\subsection{Results for the First Research Question}

The first question of the study was meant to explore whether Iranian Junior High School EFL learners possess reading self-efficacy when reading their textbook passages. To answer this question, a one sample Kolmogorov-Smirnov test was run to ensure the normality of distribution for the participants' scores on the questionnaire. This test revealed that the distribution was normal $(\mathrm{Z}=.534 p=.938>0.05)$. Then, the researchers conducted a one-sample t-test analysis on the participants' mean score on the Self-efficacy-in-Reading Questionnaire (see Table 1)

Table 1. One Sample T-Test for the Participants' Pre-treatment Mean Score on Self-efficacy Questionnaire

\begin{tabular}{|c|c|c|c|c|c|}
\hline \multicolumn{5}{|c|}{ Test value $=0$} \\
\hline $\mathrm{T}$ & Df & $\begin{array}{c}\text { Sig. } \\
\text { (2-tailed) }\end{array}$ & $\begin{array}{c}\text { Mean } \\
\text { Difference }\end{array}$ & \multicolumn{2}{|c|}{$\begin{array}{c}\text { 95\% Confidence } \\
\text { Interval of the } \\
\text { Difference }\end{array}$} \\
\hline 55.967 & 76 & .000 & 3.54675 & 3.4205 & 3.6730 \\
\hline
\end{tabular}

As is evident from the table above, the one-sample t-test results revealed a significant $\mathrm{p}$-value $[\mathrm{t}(76)=55.96, p<$ $0.05)]$. Thus, the null hypothesis for the first research question was rejected, which means that all the participants possessed self-efficacy in reading while reading their textbook passages. The first question of the study, therefore, received an affirmative response.

\subsection{Results for the Second Research Question}

The second question aimed at examining whether applying alternative reading comprehension assessment techniques improves Iranian Junior High School EFL learners' self-efficacy in reading comprehension of their textbook passages. To answer this question, the researchers conducted an independent-samples t-test analysis on the participants' performance on the Reading Self-efficacy Questionnaire after treatment. Again, before conducting the t-test, the researchers ensured the data distribution normality by running the Kolmogorov-Smirnov Test, the results of which revealed that the distribution was normal $\left(Z_{c}=0.854\right.$, $\left.p=0.459>0.05 ; Z_{e}=0.597, p=0.868>0.05\right)$. Thus, the t-test was safely run. Table 2 below shows the t-test results. 
Table 2. Independent- samples T-test for Experimental and Control Groups' performance on the post-treatment Reading Self-efficacy Questionnaire

\begin{tabular}{|c|c|c|c|c|c|c|}
\hline \multicolumn{3}{|c|}{ t-test for Equality of Means } \\
\hline \multirow{2}{*}{$\mathrm{T}$} & Df & Sig. (2-tailed) & $\begin{array}{c}\text { Mean } \\
\text { Difference }\end{array}$ & $\begin{array}{c}\text { Std. Error } \\
\text { Difference }\end{array}$ & \multicolumn{2}{|c|}{ 95\% Confidence Interval of the Difference } \\
\cline { 5 - 7 } & & .574 & 1.761 & 3.121 & -4.455 & Upper \\
\hline .564 & 75 & & &
\end{tabular}

As shown in the table, the results of the t-test revealed no significant difference between the performance of the control and experimental groups on the post-treatment Reading Self-efficacy questionnaire [ $\mathrm{t}(75)=0.564, p=0.574]$. Therefore, the null hypothesis for the second research question could not be rejected; consequently, the answer to the second question turned out to be in the negative. Thus, the use of Alternative Assessment techniques did not affect the participants' self-efficacy in reading comprehension of their English textbook passages.

\subsection{Results for the Third Research Question}

The third question was formulated to explore whether applying alternative reading comprehension assessment techniques could improve Iranian Junior High School EFL learners' performance on the reading comprehension test based on their textbook reading passages. The participants' mean scores obtained from pretest and posttest reading comprehension tests were compared via an independent-samples t-test. Again, before running this test, the normality of the distributions across the two groups' scores was checked via the Kolmogorov-Smirnov Test. The results confirmed the normality of distributions for both experimental $(Z=0.966, p=0.308)$ and control $(Z=0.819, p$ $=0.513$ ) groups. Thus, the t-test analysis was safely applied to compare the two groups. Table 3 below presents the results for the t-test.

As illustrated by the table above, the t-test results revealed a significant difference between the control group $\left(\mathrm{M}_{\mathrm{c}}=\right.$ $65.76, \mathrm{SD}=2.27$ ) and the experimental group's $\left[\mathrm{M}_{\mathrm{e}}=87.25\right.$, $\mathrm{SD}=2.94, \mathrm{t}(75)=35.81, \mathrm{p}<0.05]$ performance on the Reading Comprehension posttest. Thus, the null hypothesis for the third research question was rejected and the answer to this question was in the affirmative. This means that the experimental group significantly outperformed the control group. In other words, applying alternative reading comprehension assessment techniques improves Iranian Junior High School EFL learners' performance on the reading comprehension test based on their textbook reading passages. The effect size turned out to be quite large (Eta squared $=0.94)$, according to Cohen's [51] ratings as cited in Pallant [52], (201). Such an effect, though not unexpected in a typical EFL teaching/learning context in Iranian high schools, requires adequate checking through replications in other parallel studies before it can be considered as a conclusive result. It is worth mentioning that the results of another independent-samples t-test had indicated no significant difference between the two groups' performances on the reading comprehension pretest before treatment application $\left[\mathrm{M}_{\mathrm{c}}=62.43, \mathrm{M}_{\mathrm{e}}=62.08 ; \mathrm{t}(75)=.73, \mathrm{p}>0.05\right]$.

\section{Discussion}

The first concern of the present study was to examine current level of Iranian EFL junior high school student' self-efficacy in reading. Alternative assessment techniques and their effect on Iranian EFL learners' self-efficacy constituted the second cornerstone of the study. Finally, the effect of alternative assessment techniques on learners' performance on reading comprehension test was the third focal point for the researchers.

With regard to the first question, the results of the data analysis reject the null hypothesis indicating that the participants of the study possessed an appropriate level of self-efficacy in reading their English textbooks. In other words, the participants of the study enjoyed a considerable level of self-efficacy in reading. This finding is in agreement with that of Zare and Mobarakeh [42] which indicated that senior High school students felt confident about their ability to perform English reading tasks. Also, Shellberg's [40] study yielded similar results. His comprehensive study on exploring self-efficacy in reading revealed that students feel they are good readers, making progress in reading regardless of the reading levels. However, this finding of the study was in sharp contrast to those of Rahemi [43] and Nasrollahi and Barjasteh [44] since the participants in their study lacked an appropriate level of self-efficacy to cope with their daily reading task and exercise in an Iranian EFL context. The reason for this contradiction might be the fact that Nasrollahi and Barjasteh's [44] study was conducted on university students who were much older than the participants of the present study and that Rahemi's [43] participants were all female subjects. 
Table 3. Independent-samples t-test Results for the groups' Performance on Reading Comprehension Posttest

\begin{tabular}{|c|c|c|c|c|c|c|}
\hline \multicolumn{9}{|c|}{ t-test for Equality of Means } \\
\hline T & Df & Sig. (2-tailed) & Mean Difference & Std. Error Difference & \multicolumn{2}{|c|}{$95 \%$ Confidence Interval of the Difference } \\
\cline { 4 - 7 } & & .000 & 21.49 & 1.140 & 18.859 & Lower \\
\hline 35.81 & 75 & & & & 23.400 \\
\hline
\end{tabular}

$($ Eta squared $=0.94)$

The results of the study confirmed the null hypothesis for the second question which was meant to examine the effect of applying alternative assessment techniques on Iranian junior High school student's self-efficacy in reading. In fact, the results obtained from the data analysis indicated that the participants of the study did not reported a significant change of self-efficacy beliefs after being exposed to alternative assessment techniques for their reading comprehension. This finding is not in line with Zimbicki's [46] finding that motivation level and self-efficacy reached high levels when students were engaged in alternative assessment. Also, Alkharusi [45] reported a different finding supporting a move towards the use of more alternative assessment. The results of his study suggested that learners' self-efficacy on performance-approach goal within a classroom was dependent jointly on class gender, teaching experiences, and frequent use of alternative assessments. One reason for this contradictory finding might be due to the novelty of the alternative assessment techniques in Iranian EFL context. Perhaps, adequate exposure to such assessment would qualify learners to strengthen their self-efficacy beliefs while reading English language texts. Also, another reason can be the fact that the subjects of this study consisted of a limited number of students in intact classes. Therefore, more replications of the study with larger subject sizes are needed before this finding can be deemed conclusive.

Nevertheless, the third null hypothesis of the study was rejected since the participants in the experimental group demonstrated statistically significant improvement in their performance on the reading comprehension test compared with the participants who received traditional reading comprehension assessment. The finding of the study was in agreement with that of Alkharusi [45], who studied the effects of classroom assessment practices on students' achievement goals.

\section{Conclusions}

Although applying alternative assessment techniques did not lead to a significant effect on learners' self-efficacy in reading comprehension skill, it significantly improved their reading comprehension performance. Assessment tasks such as matching items, gap filling items and C-test items were able to create a new atmosphere of learning. Such alternative assessment techniques could provide a new ground for EFL learners to experience somewhat different ways of being assessed. In addition, alternative assessment techniques can make a great contribution to language teachers as such techniques help measure reading comprehension ability both as a product and a process [23]. They can benefit from such alternative techniques to tap into any aspect of language learning programs. The present authors' shared feeling is that teachers can handle EFL learners' individual differences through utilizing varied ways of assessment. In doing so, they can be said to be able to enhance learners' motivation and help them feel involved in the learning atmosphere.

\section{REFERENCES}

[1] R. Clement, Z. Dornyei \& K. A. Noel. Motivation, Self-Confidence and Group Cohesion in the Foreign Language Classroom, Language Learning, Vol. 44, No. 3, 417-448, 1994.

[2] R. Gardner \& W. Lambert. Attitudes and Motivation in Second Language Learning, Rowley, MA: Newbury House, 1972.

[3] E. Hilgard. Motivation in Learning Theory. In Koch (1963) Psychology: A study of Science. 5, U.S.A: McGraw-Hill, 1963.

[4] M.C. McKenna, D.J. Kear \& R.A. Ellsworth. Children's Attitudes toward Reading: A national Survey. Reading Research Quarterly, No. 30, 934-955, 1995.

[5] W. R. Gee. Encouraging ESL Students to Read, TESOL Journal, Vol. 8, No. 1, 3-7, 1999.

[6] A. Bandura. Social Foundations of Thought and Action: A Social Cognitive Theory, Englewood Cliffs, N.J.: Prentice-Hall, 1986.

[7] L Bachman. Fundamental Consideration in Language Testing, Oxford: Oxford University Press, 1990.

[8] J. C. Anderson. Assessing Reading, Cambridge: Cambridge University Press, 2000.

[9] C. Navarrete, J. Wilde, C. Nelson, R. Martinez \& G. Hargett. Informal Assessment in Educational Evaluation: Implication for Bilingual Education Programs, Washington DC: Nation Clearinghouse for Bilingual Education, 1990.

[10] E. V. Hamayan. Approaches to Alternative Assessment, Annual Review of Applied Linguistics, No. 15, 212-226, 1995.

[11] B. Harp. Assessment and Evaluation in Whole Language Programs, Norwood, MA: Christopher- Gorde Publishers, 1991.

[12] S. Dikli. Assessment at a Distance: Traditional vs. Alternative Assessments, The Turkish Online Journal of Educational Technology - TOJET, Vol. 2, No. 3, 13-19, 2003. 
[13] K. M. Bailey. Learning about Language Assessment: Dilemmas, Decisions, and Directions, Heinle \& Heinle, 1998.

[14] B. Law \& M. Eckes. Assessment and ESL, Peguis Publishers: Manitoba, Canada, 1995.

[15] M. Simonson, S. Smaldino, M. Albright \& S. Zvacek. Assessment for Distance Education (ch 11), Teaching and Learning at a Distance: Foundations of Distance Education. Upper Saddle River, NJ: Prentice-Hall, 2000.

[16] A. Brualdi. Implementing Performance Assessment in the Classroom, Practical Assessment, Research \&Evaluation, Vol. 6, No. 2, 1-3, 1998. Available online: http://ericae.net/pare/getvn.asp? $v=6 \& n=2$

[17] S. Murphy\& M.A. Smith. Writing Portfolios: A Bridge from Teaching to Assessment, Markham, Ontario: Pippin Publishing Limited, 1992.

[18] F. Z Stayter \& P. Johnston. Evaluating the Teaching and Learning of Literacy. In T. Shanahan (Ed). Reading and Writing Together: New Perspective for the Classroom. Norwood, MA: Christopher-Gordon Publishers, 253-271, 1990.

[19] K. Au, A. Scheu, K. Kawakami \& P. Herman. Assessment and Accountability in Whole Literacy Curriculum, The Reading Teacher, No. 43, 574-578, 1990.

[20] V. Perrone. Expanding Student Assessment, Alexandria, VA: Association for Supervision and Curriculum Development, 1991.

[21] C. Nuttall. Teaching Reading Skills in a Foreign Language, Oxford: Macmillan, 1996.

[22] H. A. Hughes. Testing for Language Teachers, Cambridge: Cambridge University Press, 2003.

[23] F. Mazlum Zavarag. New Tasks for Old Texts: Alternative Techniques for Reading Comprehension Assessment, Roshd FLT, No. 23, 15-22, 2009.

[24] T. J. Kennedy, J. K Nelson, M. R. L. Odell \& L. K. Austin. The ELES Attitudinal Inventory, Foreign Language Annuals, Vol. 33, No. 3, 278-287, 2000.

[25] H. D. Brown. Teaching by Principles: An Interactive Approach to Language Pedagogy, Englewood Cliffs, N. j.: Prentice Hall, 2001.

[26] A. Bandura. Self-efficacy: Toward a Unifying Theory of Behavior Change, Psychological Review, No. 84, 191-215, 1977.

[27] C. P. Wu. The Effects of Goal Orientation, Self-efficacy, and Cognitive /Metacognitive Self-regulatory Strategy Use on EFL College Students' Course Achievement, Unpublished PhD Dissertation. University of Southern California, 2006.

[28] A. Wigfield \& J. S. Eccles. The Development of Achievement Task Values: A Theoretical Analysis, Developmental Review, No. 12, 265-310, 1992.

[29] P. R. Pintrich \& D. H. Schunk. Motivation in Education: Theory, Research, and Applications, Englewood Cliffs, NJ: Prentice Hall, 1996.
[30] M. Alfassi. Reading to Learn: Effects of Combined Strategy Instruction on High School Students, Journal of Educational Research, Vol. 97, No. 4, 171-184, 2004. Retrieved from http://dx.doi.org/10.3200/JOER.97.4.171-185

[31] J. E. Ormrod. Educational Psychology: Developing Learners (3rd ed.), Upper Saddle River, NJ: Prentice Hall, 2000.

[32] F. Pajares. Self-efficacy Beliefs, Motivation and Achievements in Writing, Reading and Writing Quarterly, Vol. 19, No. 2, 139-158, 2003.

[33] P. R. Pintrich, \& D. H. Schunk. Motivation in Education: Theory, Research and Applications (2nd ed.), Englewood Cliffs, NJ: Prentice Hall, 2002.

[34] B. J. Zimmerman. Self-efficacy: An Essential Motive to Learn, Contemporary Educational Psychology, No. 25, 82-91, 2000

[35] D. H. Schunk. Social Self-interaction and Achievement Behavior, Educational Psychologist, No. 34, 219-227, 1999.

[36] H. Margolis \& P. P. McCabe. Improving Self-efficacy and Motivation: What to Do, What to Say, Intervention in School and Clinic, No. 42, 218-227, 2003.

[37] P. P. McCabe \& H. Margolis. Enhancing the Self- Efficacy of Struggling Readers, The Clearing House, Vol. 75, No. 1, 45-49, 2001

[38] Ferrara, S. L. Promote Reader Self-efficacy, Intervention in School and Clinic, Vol. 41, No. 1, 36-38, 2005.

[39] M. V. Dinthy, F. Docky \& M. Segers. Factors Affecting Students' Self-efficacy in Higher Education, Educational Research Review, No. 6, 95-108, 2011. Retrieved from http://www.elsevier.com/locate/EDUREV

[40] C. D. Shellberg. Exploring Self-efficacy in Reading, Unpublished MA Thesis, 2009. Retrieved from http://www.hamine.edu.workarea.downloadasset.aspx?id=21 47491019

[41] Y. Khajavi \& S. Ketabi. Influencing EFL Learners' Reading Comprehension and Self-Efficacy Beliefs: The Effect of Concept Mapping Strategy, Porta Linguarum, No. 17, 9-27, 2012.

[42] M. Zare \& S. D. Mobarakeh. The Relationship between Self-efficacy and Use of Reading Strategies: The Case of Iranian Senior High School Students, Studies in Literature and Language, Vol. 3, No. 3, 98-105, 2011.

[43] J. Rahemi. Self-efficacy and Iranian Senior High School Students Majoring in Humanities, Novitas-ROYAL, Vol. 1, No. 2, 98-111, 2007. Retrieved 12 December, 2013 from http:// novitasroyal.org

[44] A. Nasrollahi \& H. Barjasteh. Iranian Students' Self-efficacy and Their Language Achievements, Theory and Practice in Language Studies, Vol. 3, No. 10, 1837-1843, 2013.

[45] H. Alkharusi. Effects of Classroom Assessment Practices on Students' Achievement Goals, Educational Assessment, No. 13. 243-266, 2008

[46] D. Zimbicki. Examining the Effects of Alternative Assessment on Student Motivation and Self-efficacy, ProQuest Dissertations and Theses, 2007. Retrieved from http:www.udini.proquest.com 
[47] E. Nezami, R. Schwarzer \& M. Jerusalem. Persian (Farsi) Adaptation of the General Self-Efficacy Scale, 1996. Retrieved from:

http://userpage.fuberlin. de/ health/persean.htm

[48] J. L. Jinks \& V. L. Morgan. Children's Perceived Academic Self-efficacy: An Inventory, 1999. Retrieved from http://www.coe.ilstu.edu/scienceed/jinks/efficacypub 97htm.

[49] E. K. Horwitz. The Beliefs about Language Learning of Beginning University Foreign Language Students, Modern Language Journal, No. 72, 283-294, 1988.
[50] R. Schwarzer \& M. Jerusalem. Generalized Self-Efficacy Scale. In Weinman, J. S. Wright \& M Johnson (eds.) Measures in Health Psychology: A User's Portfolio, Causal and Control Beliefs, pp. 35-37, Windsor England: NFER-NELSON, 1995.

[51] J. W. Cohen. Statistical Power Analysis for the Behavioral Sciences (2nd ed.), Hillsdale, NJ: Lawrence Erlbaum Associates, 1988.

[52] J. Pallant. SPSS Survival Manual: A Step by Step Guide to Data Analysis Using SPSS for Windows (Version 12), Allen \& Unwin, 2005. 